\title{
A Comparison of Figure-of-8-Suture vs Manual Compression for Venous Access Closure after Cardiac Procedures: An Updated Meta-Analysis.
}

\author{
Mark Terence Mujer ${ }^{1}$, Abdullah Al-abcha ${ }^{1}$, Jairus Flores ${ }^{2}$, Yehia Saleh ${ }^{1}$, and Peter \\ Robinson ${ }^{3}$ \\ ${ }^{1}$ Michigan State University \\ ${ }^{2}$ University of the Philippines Manila College of Medicine \\ ${ }^{3}$ Pat and Jim Calhoun Cardiology Center
}

May 18, 2020

\begin{abstract}
Background Manual compression (MC) is the current standard to achieve post-procedural hemostasis in patients who need venous vascular access closure after cardiovascular procedures. Figure-of-8 (F8) suture for venous access closure has been reported to be a safe and efficacious alternative to MC. Methods A systematic search was done using PubMed, Google Scholar, EMBASE, SCOPUS and ClinicalTrials.gov without language restriction up until April 15, 2020 for studies comparing F8 suture vs MC. Risk ratio (RR) and mean difference (MD) with $95 \%$ confidence interval (CI) were calculated using a random effects model. Results Time to achieve hemostasis was significantly reduced in the F8 arm [MD -21.04 mins (95\% CI: -35.66 to -6.42; $\mathrm{p}=.005)]$. Access site bleeding was significantly lower in the F8 group [RR 0.35 (95\% CI: 0.18 to 0.66 ; $\mathrm{p}=0.001$ )] along with a lower incidence of hematoma formation [RR $0.42(95 \%$ CI 0.26 to $0.67 ; \mathrm{p}=0.0003)$ ]. There was no significant difference in rates of fistula or pseudoaneurysm formation between the two groups. Overall access site complications were lower in the F8 arm [RR 0.38 (95\% CI: 0.26 to $0.55 ; \mathrm{p}<0.00001)$ ] and the effect was more pronounced for sheaths [?]10 Fr [RR 0.33 (95\% CI: 0.18 to $0.60 ; \mathrm{p}=0.0003)$ ]. There was lower post-procedural protamine use in the F8 group [RR 0.07 (95\% CI:0.01 to $0.36 ; \mathrm{p}=0.001)]$. Conclusion For large-bore venous access closure, the F8 suture results in a shortened time to achieve hemostasis along with a lower overall risk of access site complications and post-procedural protamine use.
\end{abstract}

Title: A Comparison of Figure-of-8-Suture vs Manual Compression for Venous Access Closure after Cardiac Procedures: An Updated Meta-Analysis.

Authors: Mark Terence Mujer MD ${ }^{1}$ Abdullah Al-Abcha MD ${ }^{1}$, Jairus Flores MD ${ }^{2}$

, Yehia Saleh MD ${ }^{1}$, Peter Robinson $\mathrm{MD}^{3}$

\section{Affiliations:}

${ }^{1}$ Department of Medicine, Michigan State University, East Lansing, MI, USA. ${ }^{2}$ University of the Philippines College of Medicine, Manila, Philippines.

${ }^{3}$ Pat and Jim Calhoun Cardiology Center, University of Connecticut, Farmington, CT, USA.

\section{Corresponding Author:}

Mark Terence Mujer, MD

Department of Medicine 
Michigan State University, 788 Service Road

Room B301, East Lansing, MI 48824, USA

Email address: Mujermar@msu.edu

Phone number: (517)-580-2080

Fax: (517)-432-2759

ORCID ID: 0000-0001-8148-0883

Key Words: Figure of Eight Suture, Manual Compression, Venous Closure.

\section{Contributorship Statement:}

MM, AA and YS conceptualized the work, gathered and interpreted the data, and drafted the initial manuscript. JF created the tables and figures. PR performed a critical revision of the manuscript.

MM and PR finalized submitted material.

Funding: No funding was received for this manuscript.

Competing Interests: All authors declare that there is no conflict of interest.

Acknowledgement: None.

A Comparison of Figure-of-8-Suture vs Manual Compression for Venous Access Closure after Cardiac Procedures: An Updated Meta-Analysis.

\section{ABSTRACT}

\section{Background}

Manual compression (MC) is the current standard to achieve post-procedural hemostasis in patients who need venous vascular access closure after cardiovascular procedures. Figure-of-8 (F8) suture for venous access closure has been reported to be a safe and efficacious alternative to MC.

\section{Methods}

A systematic search was done using PubMed, Google Scholar, EMBASE, SCOPUS and ClinicalTrials.gov without language restriction up until April 15, 2020 for studies comparing

F8 suture vs MC. Risk ratio (RR) and mean difference (MD) with 95\% confidence interval (CI) were calculated using a random effects model.

\section{Results}

Time to achieve hemostasis was significantly reduced in the F8 arm [MD -21.04 mins (95\% CI: -35.66 to $-6.42 ; \mathrm{p}=.005)$ ]. Access site bleeding was significantly lower in the F8 group [RR 0.35 (95\% CI: 0.18 to 0.66 ; $\mathrm{p}=0.001)$ ] along with a lower incidence of hematoma formation [RR $0.42(95 \%$ CI 0.26 to $0.67 ; \mathrm{p}=0.0003)$ ]. There was no significant difference in rates of fistula or pseudoaneurysm formation between the two groups. Overall access site complications were lower in the F8 arm [RR 0.38 (95\% CI: 0.26 to $0.55 ; \mathrm{p}<0.00001)$ ] and the effect was more pronounced for sheaths [?]10 Fr [RR 0.33 (95\% CI: 0.18 to $0.60 ; \mathrm{p}=0.0003)$ ]. There was lower post-procedural protamine use in the F8 group [RR 0.07 (95\% CI:0.01 to 0.36; $\mathrm{p}=0.001)$ ].

\section{Conclusion}

For large-bore venous access closure, the F8 suture results in a shortened time to achieve hemostasis along with a lower overall risk of access site complications and post-procedural protamine use.

\section{Introduction}


In patients undergoing cardiac procedures, the use of large sheath sizes for venous vascular access is not uncommon. Manual compression is the current standard to achieve post-procedural hemostasis. Although some studies have previously reported favorable outcomes in utilizing arterial vascular closure devices for venous access closure, data on venous vascular closure devices are limited.

Figure-of-8 (F8) suture is an alternative approach for large-bore venous access closure. Prior studies have evaluated the safety and efficacy of the F8 suture technique through venography or vascular ultrasound. (1-3) The first reported use of the F8 suture was done by Bagai and Zhao who used the technique to achieve adult femoral venous access hemostasis and reported success in large caliber sheaths (8 to $21 \mathrm{Fr}$ ). As a result, F8 has been used in achieving venous hemostasis with sheaths as large as 24 Fr. (1)

In the F8 suture, a large curved needle with a 0-silk suture is passed through the subcutaneous tissue around 5-10 $\mathrm{mm}$ under the access sheath with care taken not to insert the needle deep enough as to ligate the femoral vein or artery. A significant amount of subcutaneous tissue is included to contribute to compression and hemostasis. The needle is then brought cranially to the sheath insertion point and is inserted again in the same initial direction through the subcutaneous tissue, hence a figure of eight stitch is performed [Figure 1]. After the sheaths are removed, the suture is tightened and knotted. The site is observed for a few minutes without utilization of manual compression. A sterile gauze is placed followed by monitoring for any signs of bleeding. Sutures are typically removed the following morning. (4-6)

Our study sought to determine the efficacy, impact and safety of F8 suture in comparison to manual compres-

sion for large-bore venous access closure. Nine studies composed of seven observational and two randomized controlled trials (RCTs) have been included in this updated meta-analysis.

\section{Methods2.1 Search Strategy}

The Preferred Reporting Items for Systematic Reviews and Meta-Analysis (PRISMA) guidelines was used in this meta-analysis. A systematic search was done using PubMed, Google Scholar, EMBASE, SCOPUS and ClinicalTrials.gov without language restriction up until April 15, 2020 by two authors (MM and AA). Studies comparing figure-of- 8 suture vs manual compression were compared. The search included the following keywords: manual compression, manual pressure, figure of eight, figure of 8 , fellow's stitch, z-stitch, venous closure, vascular closure.

\subsection{Study Selection}

The following criteria were used for study selection: [1] The study was performed on adults [?] 18 years of age. [2] The study compared figure-of-eight suture vs manual compression. [3] The study reported atleast one clinical outcome.

\subsection{Data Extraction}

Disagreements between the two authors (MM and AA) were resolved through internal discussion. The following details were collected from each study: Author, design, study population, male sex, age, mean CHA2DS2VASc score, laboratory parameters such as pre-procedural international normalized ratio (INR) and post-procedural activated clotting time (ACT), type of procedure, location of access sites, number of access sites and procedural success rate.

\subsection{Clinical Outcomes}

The study collected and evaluated the following clinical outcomes: [1] time to hemostasis [2] access site complications [3] fistula formation [4] pseudoaneurysm formation [5] access site bleeding [6] access site hematoma [7] post-procedural protamine use.

\subsection{Statistical Analysis}

Review Manager (RevMan), version 5.3 (The Cochrane Collaboration, Copenhagen, Denmark) was used for statistical analysis. The DerSimonian-Laird random-effects model was used to estimate the risk ratios (RR) 
and mean difference (MD) with the corresponding $95 \%$ confidence interval (CI). Two-sided p values $<0.05$ were considered statistically significant. Higgins and Thompson $\mathrm{I}^{2}$ statistic was used to assess heterogeneity.

\section{Results3.1 Search Results}

A PRISMA flow chart has been included [Figure 2]. A total of 121 citations were identified after an intensive search process, 23 articles were assessed for eligibility and 14 were excluded after screening. Nine studies were found to be eligible based on the inclusion criteria.(4-12)

\subsection{Study Characteristics}

In this meta-analysis, 9 eligible studies were included, composed of 7 observational and 2 RCTs with a total of 2,338 patients. The majority of the study population were males. 1,175 (50.26\%) of patients received the F8 suture of which mean $\pm \mathrm{SD}$ age ranged from $55 \pm 12.4$ to $63 \pm 11$ years and baseline $\mathrm{INR} \pm \mathrm{SD}$ ranged from $1.4 \pm 0.5$ to $2.6+-0.6$. The majority of the procedures done were AF catheter ablation. Access sites reported were the left and right femoral veins. The success rate of the F8 suture ranged from $91.7 \%$ to $100 \%$ in the included studies

\section{[Table 1].}

\subsection{Outcomes}

\subsubsection{Time to Hemostasis}

Time to achieve hemostasis was significantly reduced in the F8 arm [MD -21.04 mins (95\% CI: -35.66 to $-6.42 ; \mathrm{p}=.005)$ ] [Figure 3.1] .

\subsubsection{Overall Access Site Complications}

Overall access site complications were lower in the F8 arm [RR 0.38 (95\% CI:0.26 to 0.55; p<0.00001)] [Figure 3.2] .

\subsubsection{Access Site Complications for Sheaths [?] $10 \mathrm{Fr}$}

Access site complications for sheaths [?]10 Fr were lower in the F8 arm [RR 0.33 (95\% CI: 0.18 to 0.60; $\mathrm{p}=0.0003)$ ] [Figure 3.3].

\subsubsection{Fistula Formation}

There was no significant difference in the rate of fistula formation [RR 0.67 (95\% CI: 0.18 to 2.41; p=0.54)] between the two groups[Figure 3.4] .

\subsubsection{Pseudoaneurysm Formation}

There was no significant difference in the occurrence of pseudoaneurysm [RR 0.47 (95\% CI 0.16 to 1.42; $\mathrm{p}=0.18)$ ] [Figure 3.5] .

3.3.6 Access site Hematoma

Access site hematoma formation was lower in the F8 arm [RR 0.42 (95\% CI: 0.26 to $0.67 ; \mathrm{p}=0.0003)$ ] [Figure 3.6].

\subsubsection{Access Site Bleeding}

Access site bleeding was significantly lower in the F8 group [RR 0.35 (95\% CI: 0.18 to $0.66 ; \mathrm{p}=0.001$ )] [Figure 3.7] .

\subsubsection{Post-Procedural Protamine Use}

Use of protamine after the procedure was significantly lower in the F8 arm [RR 0.07 (95\% CI:0.01 to 0.36; $\mathrm{p}=0.001)$ ] [Figure 3.8] . 
Test of heterogeneity was low for rates of fistula, hematoma and pseudoaneurysm formation, and access site complications. Test of heterogeneity was moderate for access site bleeding and was high for time to achieve hemostasis and post-procedural protamine use.

\section{Discussion}

The main findings of our study are the following: [1] Time to achieve hemostasis was significantly shorter in the F8 group. [2] There is no difference between F8 and MC in pseudoaneurysm or fistula formation. [3] Access site hematoma and access site bleeding were lower in the F8 group . [4] Overall access site complications were lower in the F8 group with a more pronounced effect seen in sheaths [?] 10 Fr. [5] Post-procedural protamine use was higher in the manual compression group.

Vascular access site complications are known to occur in cardiac procedures and are associated with increased morbidity and prolonged hospital stay. $(13,14)$ The use of large venous sheaths, periprocedural anticoagulation and multiple sites of puncture contribute to these complications. A demographic shift towards elderly patients receiving cardiac procedures can contribute to an increase in complication rates. Techniques to achieve effective hemostatic control are thus of paramount importance to prevent these complications. Manual compression is the current standard for venous access closure and has been demonstrated to be effective in achieving post-procedural hemostasis; however, its use is associated with patient discomfort, need for additional staff and a longer patient stay in the procedural lab. (15) A period of absolute bed rest with limited limb movement is required to achieve hemostasis through MC. Various techniques such as pressure dressing and closure devices have been utilized for venous vascular hemostasis and have been reported to be efficacious. These techniques are associated with increased cost, risk of device failure and reported complications such as infections and thromboembolism.(16-22)

The F8 suture has been branded as the "Fellow's Stitch" due to its simple technique compared to other suture delivery systems.(2) F8 can be performed in a very short duration (30-60s), and its failure has been attributed to inadequate knot tie or suture break. $(4,6)$ Our study demonstrated on average a 21 minute reduction in the time needed to achieve satisfactory hemostasis when utilizing the F8 suture compared to traditional MC. Pracon et al., using doppler-duplex assessment of the groins, reported a slightly compressed mean vein diameter with the F8 stitch in place. This gives insight to the stitch's mechanism of action of utilizing the subcutaneous tissue pad to exert pressure on the puncture site. The pressure exerted by the compression is sufficient for hemostasis but maintains the vein's lumen dimensions. Venous thrombosis is a possible concern with a compressed vein diameter. Cilingiroglu et al demonstrated vasoconstriction at the sheath entry point through venography after F8 closure but vascular ultrasound following suture removal demonstrated resolution of the vasoconstriction along with femoral vein compressibility and the absence of thrombus. (1) Our study sought to determine and compare thromboembolic rates. Five of eight studies included thromboembolism as an outcome but no thromboembolic complications were observed aside from 2 events in the Issa $2015 \mathrm{MC}$ arm, both of which were transient ischemic attacks.(4-6)

The use of $\mathrm{F} 8$ resulted in a $62 \%$ reduction in overall access site complications. The size of the sheaths used in the included studies varied widely, with reported sizes of up to $22 \mathrm{Fr}$, demonstrating safety and efficacy across a wide range of large venous sheath sizes. The reduction in access site complications may be explained by a shorter time to hemostasis in comparison to the MC group.

Although there were differences in procedural protocols in the included studies, we found a lower need for post-procedural protamine use in the F8 arm. This can lead to lower rates of thromboembolic complications and prevention of other commonly-reported side effects of protamine use such as anaphylaxis, hypotension and bradycardia.(23) Additional cost for suture material are lower in comparison to the amount saved from the use of protamine sulfate (\$1.53 vs $\$ 7.60)$ (8)

Aside from outcomes reported in this study, Payne et al reported a reduced time to extubation and a reduced recovery time in the electrophysiology lab in their study with the use of F8 suture in comparison to MC. A subgroup analysis done in the study conducted by Jensen et al. showed a significantly higher rate of vascular complications in the manual compression arm $(9.4 \%$ vs $0 \% ; \mathrm{p}=0.045)$ in patients with obesity 
(body mass index [?]30 $\mathrm{kg} / \mathrm{m}^{2}$ ), a factor which should be considered in the decision to use MC. Of note, most of the studies included patients who underwent ablation for atrial fibrillation. The efficacy and safety of the F8 suture may possibly be greater in patients undergoing procedures which do not require continued anticoagulation.

\section{Study Limitations}

The following limitations should be considered in the interpretation of the results of this meta-analysis. Most of the studies included were observational. Some included studies were nonrandomized and retrospective in nature which may potentially have selection bias. A wide variety of venous sheaths sizes were used in the different studies. Although some studies reported utilizing sheaths $<8 \mathrm{Fr}$, procedural review showed that they were closed concomitantly with a bigger sheath size utilizing a single F8 suture. 4 studies did not monitor or report post-procedural thromboembolic complications. Included studies had variations in ablation protocols, protamine administration and timing of sheath removal. Publication bias is an inherent characteristic of any meta-analysis.

\section{Conclusion}

F8 is a safe and efficacious alternative to MC in large-bore venous access closure and its use results in a shortened time to hemostasis with a lower overall risk of access site complications and post-procedural protamine use. Further RCTs are needed to confirm these results.

\section{TABLES AND FIGURES}

Table 1 Study Characteristics

\begin{tabular}{|c|c|c|c|c|c|c|c|c|c|c|c|c|c|}
\hline sudy & | Dosisn & 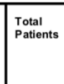 & 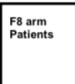 & 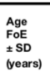 & 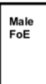 & $\begin{array}{l}\text { Monon } \\
\text { chansas } \\
\text { csoss }\end{array}$ & 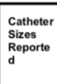 & 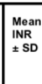 & 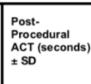 & 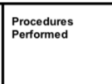 & 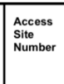 & 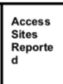 & 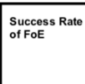 \\
\hline \begin{tabular}{|l|l|l|} 
Bss 2015 \\
\end{tabular} & 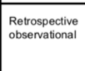 & 376 & \begin{tabular}{|l}
123 \\
\end{tabular} & $\begin{array}{l}65.3311 \\
20\end{array}$ & 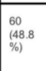 & $3.0 \pm 1.7$ & $\begin{array}{ll}g F_{1} \\
11.5 \mathrm{Ft}\end{array}$ & 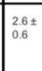 & 326557.0 & 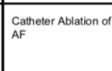 & 4 & 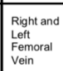 & $98.4 \%$ \\
\hline Ayremir 2016 & 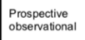 & 200 & 100 & $\begin{array}{l}55 \pm \\
524 \\
124\end{array}$ & 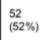 & NR & $15 \mathrm{Fr}$ & NR & NR & 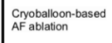 & 1 & 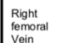 & $100 \%$ \\
\hline $\begin{array}{l}\text { Latathmanasdoss } \\
2017\end{array}$ & 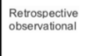 & 284 & \begin{tabular}{|l|}
179 \\
\end{tabular} & 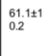 & 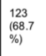 & $1.9 \pm 1.3$ & $8.5 \mathrm{Fr}$ & 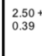 & $315 \pm 58$ & $\begin{array}{l}\text { Canteler ablation of } \\
\text { AF }\end{array}$ & 3 & 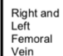 & $100 \%$ \\
\hline Amalay 2017 & 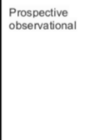 & 407 & 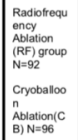 & 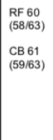 & 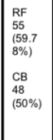 & 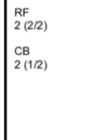 & 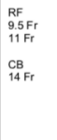 & 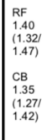 & 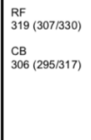 & 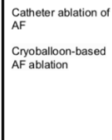 & $\begin{array}{l}\mathrm{RF} 4 \mathrm{4} \\
\mathrm{CB} 2\end{array}$ & 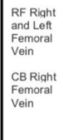 & $100 \%$ \\
\hline \begin{tabular}{|l|l|} 
Pracon 2018 \\
\end{tabular} & 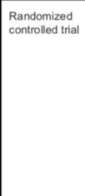 & 90 & 80 & $\begin{array}{l}5090 \pm 2 \\
0.5\end{array}$ & $30 \%$ & NR & 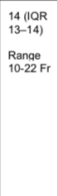 & NR & NR & 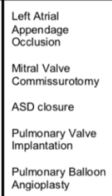 & NR & 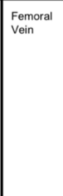 & $9.17 \%$ \\
\hline Othada 2018 & 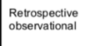 & 517 & 270 & ${ }^{63+1}$ & \begin{tabular}{|l|}
$\begin{array}{l}218 \\
(81)\end{array}$ \\
\end{tabular} & NR & 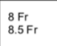 & \begin{tabular}{|l}
1874 \\
0.744
\end{tabular} & $325: 34$ & 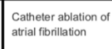 & 3 & 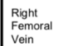 & $100 \%$ \\
\hline Pasme 2018 & 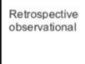 & 104 & 62 & 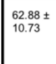 & 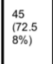 & NR & $8 \mathrm{Fr}$ & $\mid \begin{array}{l}1.4 \pm \\
0.5\end{array}$ & $\begin{array}{l}276.5883521 \\
\end{array}$ & 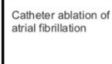 & 4 & 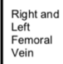 & 100\% \\
\hline Kumara 2019 & 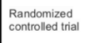 & 70 & 35 & $\mid \begin{array}{l}28,1 \pm \\
9.5\end{array}$ & 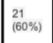 & NR & 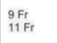 & NR & $200 \div 73$ & 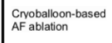 & $30 \pm 10$ & 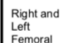 & $100 \%$ \\
\hline
\end{tabular}




\begin{tabular}{|c|c|c|c|c|c|c|c|c|c|c|c|c|c|}
\hline & & & & & & & & & & & & Vein & \\
\hline Jensen 2020 & 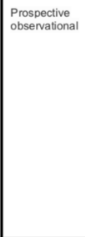 & 290 & 158 & \begin{tabular}{|l}
$664 \pm$ \\
13.2
\end{tabular} & \begin{tabular}{|l}
106 \\
67.1 \\
$6 \% 7$
\end{tabular} & NR & $\begin{array}{l}14.8 \pm \\
28 \mathrm{FF}\end{array}$ & NR & NR & 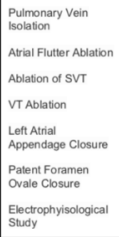 & NR & $\begin{array}{l}\text { Femorala } \\
\text { Veiin }\end{array}$ & $98.7 \%$ \\
\hline
\end{tabular}

Figure 1 Figure of Eight Suture
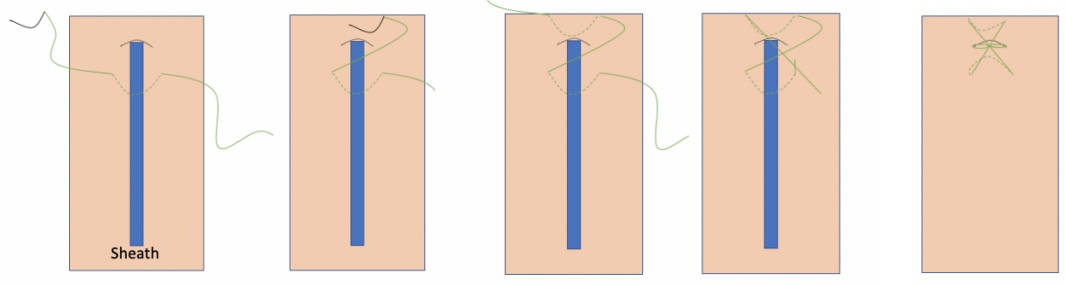

Figure 2 Prisma Flow Chart 


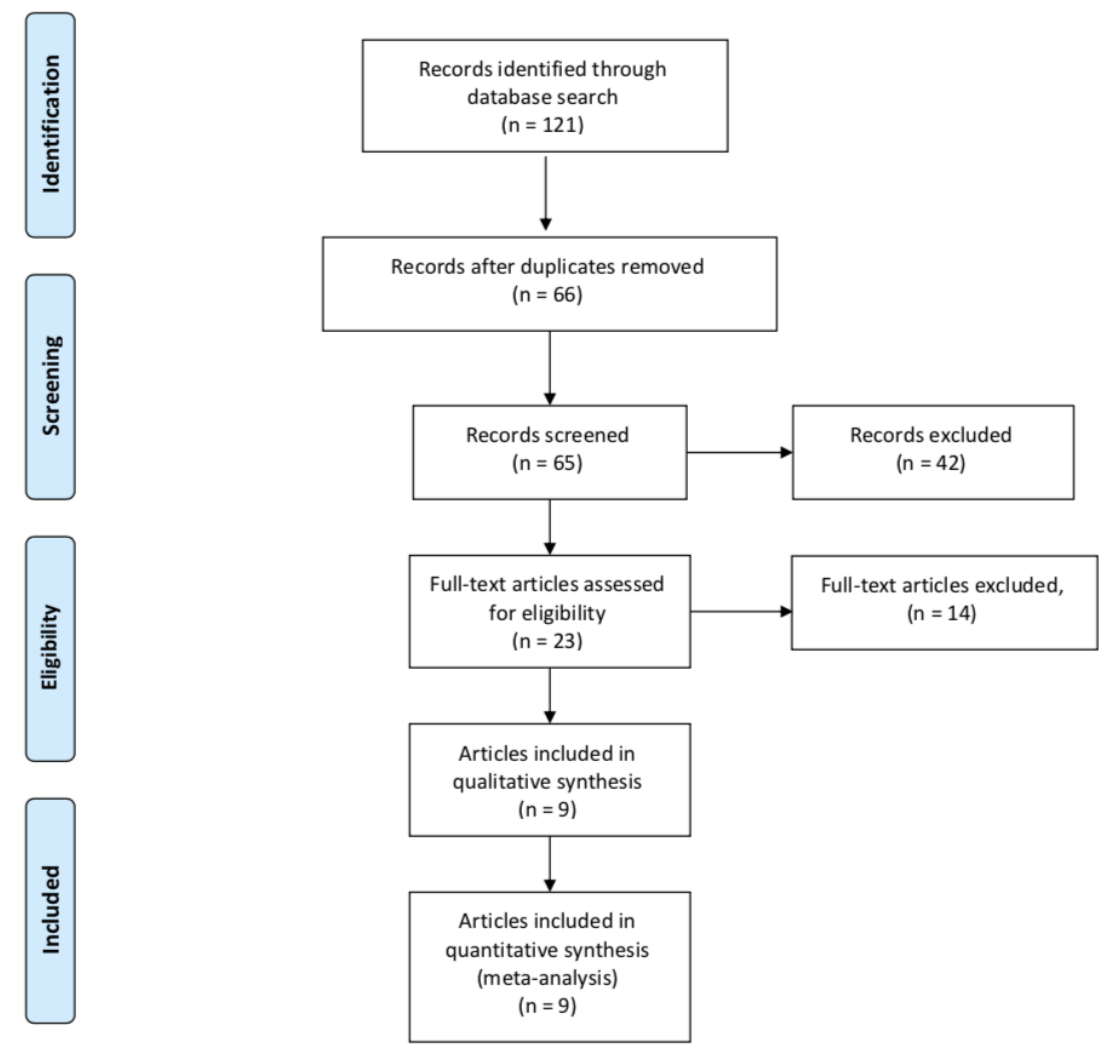

From: Moher D, Liberati A, Tetzlaff J, Altman DG, The PRISMA Group (2009). Preferred Reporting /tems for Systematic Reviews and MetaAnalyses: The PRISMA Statement. PLoS Med 6(7): e1000097. doi:10.1371/journal.pmed 1000097

For more information, visit www.prisma-statement.org.

Figure 3.1 Overall time to achieve hemostasis

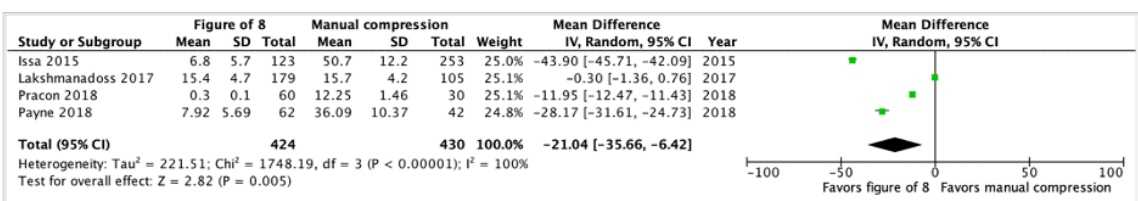

Figure 3.2 Overall access site complications 


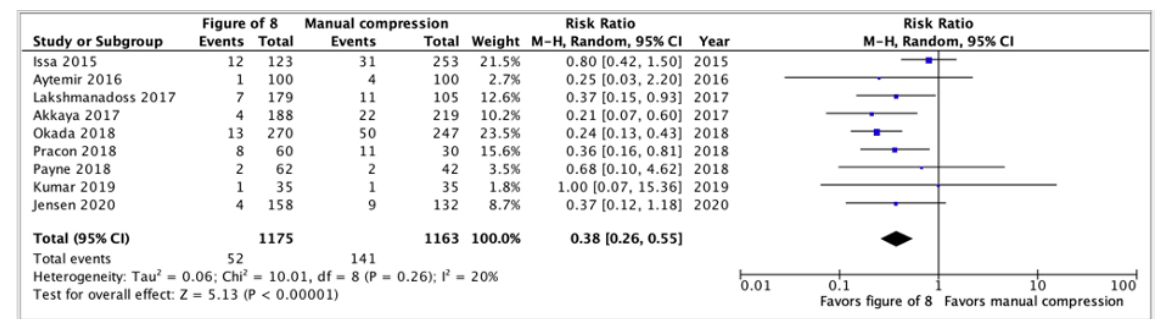

Figure 3.3 Access site complications for sheaths [?] $10 \mathrm{Fr}$

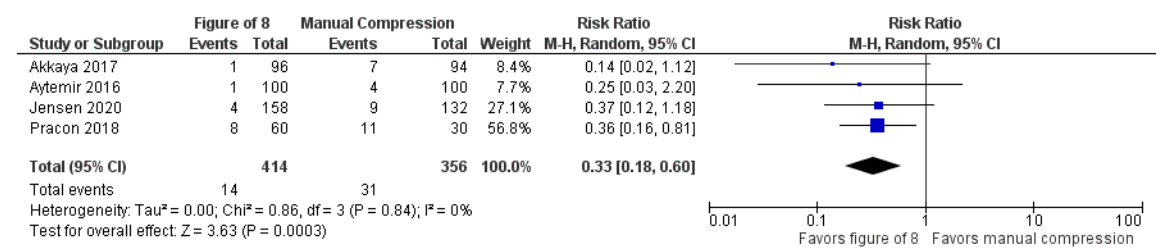

Figure 3.4 Fistula formation

\begin{tabular}{|c|c|c|c|c|c|c|c|c|c|c|}
\hline Study or Subgroup & \multicolumn{2}{|c|}{ Figure of 8} & \multicolumn{2}{|c|}{ Manual compression } & Weight & $\begin{array}{c}\text { Risk Ratio } \\
\text { M-H, Random, } 95 \% \mathrm{CI}\end{array}$ & \multirow{2}{*}{ Year } & \multicolumn{3}{|c|}{$\begin{array}{c}\text { Risk Ratio } \\
\text { M-H, Random, } 95 \% \mathrm{CI}\end{array}$} \\
\hline & 0 & 123 & 0 & 253 & & & & & & \\
\hline Aytemir 2016 & 0 & 100 & 0 & 100 & & Not estimable & 2016 & & & \\
\hline Lakshmanadoss 2017 & 2 & 179 & 2 & 105 & $43.8 \%$ & $0.59[0.08,4.10]$ & 2017 & & & \\
\hline Akkaya 2017 & 1 & 188 & 1 & 219 & $21.7 \%$ & $1.16[0.07,18.50]$ & 2017 & & & \\
\hline Payne 2018 & 1 & 62 & 0 & 42 & $16.4 \%$ & $2.05[0.09,49.09]$ & 2018 & & & \\
\hline Pracon 2018 & 0 & 60 & 0 & 30 & & Not estimable & 2018 & & & \\
\hline Okada 2018 & 0 & 270 & 0 & 247 & & Not estimable & 2018 & & & \\
\hline Jensen 2020 & 0 & 158 & 2 & 132 & $18.1 \%$ & $0.17[0.01,3.45]$ & 2020 & & & \\
\hline Total $(95 \% \mathrm{Cl})$ & & 1140 & & 1128 & $100.0 \%$ & $0.67[0.18,2.41]$ & & & & \\
\hline \multirow{2}{*}{\multicolumn{8}{|c|}{$\begin{array}{l}\text { Total events } \\
\text { Heterogeneity: } \text { Tau }^{2}=0.00 ; \text { Chi }^{2}=1.46, d f=3 \\
\text { Test for overall effect: } Z=0.62(P=0.54)\end{array}$}} & & & \\
\hline & & & & & & & & 0.01 & $\begin{array}{l}0.1 \\
\text { Favors figure of } 8\end{array}$ & $\begin{array}{l}10 \\
10\end{array} \frac{10}{100}=0$ \\
\hline
\end{tabular}

Figure 3.5 Pseudoaneurysm formation

\begin{tabular}{|c|c|c|c|c|c|c|c|c|c|c|}
\hline \multirow{2}{*}{ Study or Subgroup } & \multicolumn{2}{|c|}{$\begin{array}{l}\text { Figure of } 8 \\
\text { Events Total }\end{array}$} & \multicolumn{2}{|c|}{ Manual compression } & Weight & $\begin{array}{c}\text { Risk Ratio } \\
\text { M-H, Random, } 95 \% \mathrm{Cl}\end{array}$ & \multirow{2}{*}{$\frac{\text { Year }}{2015}$} & \multicolumn{3}{|c|}{$\begin{array}{c}\text { Risk Ratio } \\
\text { M-H, Random, } 95 \% \mathrm{CI}\end{array}$} \\
\hline & 1 & 123 & 3 & 253 & $24.1 \%$ & $0.69[0.07,6.52]$ & & & $=1$ & \\
\hline Akkaya 2017 & 0 & 188 & 1 & 219 & $12.0 \%$ & $0.39[0.02,9.47]$ & 2017 & & & \\
\hline Lakshmanadoss 2017 & 0 & 179 & 2 & 105 & $13.3 \%$ & $0.12[0.01,2.43]$ & 2017 & & & + \\
\hline Okada 2018 & 0 & 270 & 1 & 247 & $12.0 \%$ & $0.31[0.01,7.45]$ & 2018 & & & \\
\hline Payne 2018 & 1 & 62 & 0 & 42 & $12.1 \%$ & $2.05[0.09,49.09]$ & & & & - \\
\hline Kumar 2019 & & 35 & 0 & & $12.2 \%$ & $3.00[0.13,71.22]$ & 2019 & & & \\
\hline Jensen 2020 & 0 & 158 & 4 & 132 & $14.4 \%$ & $0.09[0.01,1.71]$ & 2020 & & & - \\
\hline Total $(95 \% \mathrm{Cl})$ & & 1015 & & 1033 & $100.0 \%$ & $0.47[0.16,1.42]$ & & & & \\
\hline \multirow{2}{*}{\multicolumn{8}{|c|}{$\begin{array}{l}\text { Total events } \\
\text { Heterogeneity: } \text { Tau }^{2}=0.00 ; \mathrm{Ch}^{2}=4.37, \mathrm{df}=6(\mathrm{P}=0.63) ; \mathrm{I}^{2}=0 \% \\
\text { Test for overall effect: } Z=1.34(\mathrm{P}=0.18)\end{array}$}} & & & \\
\hline & & & & & & & & 0.01 & $\begin{array}{c}0.1 \\
\text { Favors figure of } 8\end{array}$ & \begin{tabular}{|l}
10 \\
10 \\
Favors manual compression
\end{tabular} \\
\hline
\end{tabular}

Figure 3.6 Access site hematoma

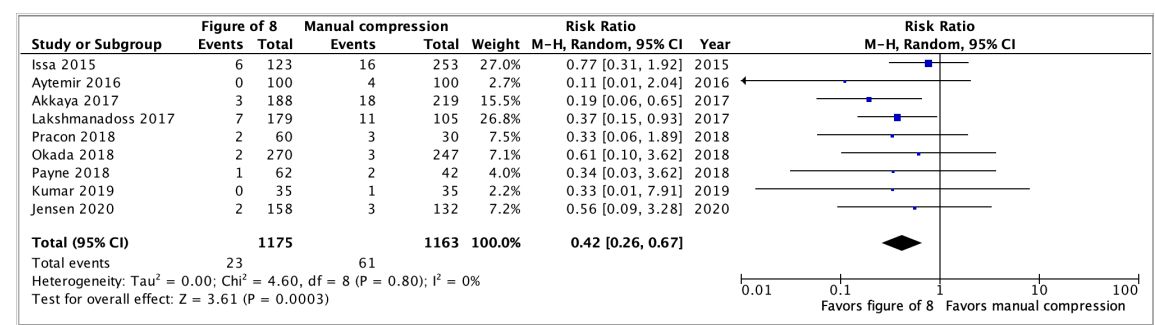

Figure 3.7 Access site bleeding 


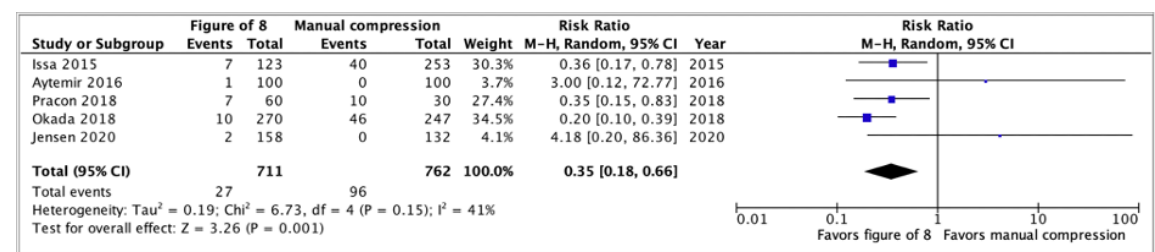

Figure 3.8 Post-procedural protamine use

\begin{tabular}{|c|c|c|c|c|c|c|c|c|}
\hline Study or Subgroup & \multicolumn{2}{|c|}{ Figure of 8} & \multicolumn{2}{|c|}{ Manual compression } & Weight & \multirow[t]{2}{*}{$\begin{array}{l}\text { Risk Ratio } \\
\text { M-H, Random, } 95 \% \mathrm{Cl} \\
\end{array}$} & \multicolumn{2}{|c|}{$\begin{array}{l}\text { Risk Ratio } \\
\text { M-H, Random, } 95 \% \mathrm{CI}\end{array}$} \\
\hline Issa 2015 & 2 & 123 & 192 & 253 & $31.4 \%$ & & 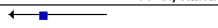 & \\
\hline Payne 2018 & 3 & 62 & 42 & 42 & $34.9 \%$ & $0.06[0.02,0.16]$ & & \\
\hline Pracon 2018 & 4 & 60 & 7 & 30 & $33.7 \%$ & $0.29[0.09,0.90]$ & & \\
\hline Total $(95 \% \mathrm{Cl})$ & & 245 & & 325 & $100.0 \%$ & $0.07[0.01,0.36]$ & & \\
\hline \multirow{2}{*}{\multicolumn{7}{|c|}{$\begin{array}{l}\text { Total events } \\
\text { Heterogeneity: } \text { Tau }^{2}=1.68 ; \text { Chi }^{2}=11.44, \quad \mathrm{df}^{2}=21 \\
\text { Test for overall effect: } Z=3.19(P=0.003) ; I^{2}=83 \% \\
\end{array}$}} & & \\
\hline & & & & & & & $\begin{array}{l}1 \\
0.1 \\
\text { Favors figu }\end{array}$ & $\begin{array}{c}10 \\
10 \\
\text { Favors manual compression } \\
\end{array}$ \\
\hline
\end{tabular}

\section{REFERENCES}

1. Cilingiroglu M, Salinger M, Zhao D, Feldman T. Technique of temporary subcutaneous "Figure-of-Eight" sutures to achieve hemostasis after removal of large-caliber femoral venous sheaths. Catheter Cardiovasc Interv. 2011;78(1):155-60.

2. Morgan GJ, Waragai T, Eastaugh L, Chaturvedi RC, Lee KJ, Benson L. The fellows stitch: large caliber venous hemostasis in pediatric practice. Catheter Cardiovasc Interv. 2012;80(1):79-82.

3. Zhou Y, Guo Z, Bai Y, Zhao X, Qin Y, Chen S, et al. Femoral venous hemostasis in children using the technique of "figure-of-eight" sutures. Congenit Heart Dis. 2014;9(2):122-5.

4. Issa ZF, Amr BS. Venous hemostasis postcatheter ablation of atrial fibrillation while under therapeutic levels of oral and intravenous anticoagulation. J Interv Card Electrophysiol. 2015;44(2):97-104.

5. Aytemir K, Canpolat U, Yorgun H, Evranos B, Kaya EB, Sahiner ML, et al. Usefulness of 'figure-ofeight' suture to achieve haemostasis after removal of 15-French calibre femoral venous sheath in patients undergoing cryoablation. Europace. 2016;18(10):1545-50.

6. Pracon R, Bangalore S, Henzel J, Cendrowska-Demkow I, Pregowska-Chwala B, Tarnowska A, et al. A randomized comparison of modified subcutaneous "Z"-stitch versus manual compression to achieve hemostasis after large caliber femoral venous sheath removal. Catheter Cardiovasc Interv. 2018;91(1):105-12.

7. Lakshmanadoss U, Wong WS, Kutinsky I, Khalid MR, Williamson B, Haines DE. Figure-of-eight suture for venous hemostasis in fully anticoagulated patients after atrial fibrillation catheter ablation. Indian Pacing Electrophysiol J. 2017;17(5):134-9.

8. Payne J, Bickel T, Gautam S. Figure-of-eight sutures for hemostasis result in shorter lab recovery time after ablation for atrial fibrillation. Pacing Clin Electrophysiol. 2018.

9. Okada M, Inoue K, Tanaka K, Ninomiya Y, Hirao Y, Oka T, et al. Efficacy and Safety of Figure-of-Eight Suture for Hemostasis After Radiofrequency Catheter Ablation for Atrial Fibrillation. Circ J. 2018;82(4):95664.

10. Jensen CJ, Schnur M, Lask S, Attanasio P, Gotzmann M, Kara K, et al. Feasibility of the Figureof-8-Suture as Venous Closure in Interventional Electrophysiology: One Strategy for All? Int J Med Sci. 2020;17(7):965-9.

11. Akkaya E, Berkowitsch A, Zaltsberg S, Deubner N, Greiss H, Hain A, et al. Safety and feasibility of percutaneous skin closure using purse-string suture compared with compression bandage after pulmonary vein isolation. J Cardiovasc Electrophysiol. 2017;28(9):1048-57. 
12. Kumar V, Wish M, Venkataraman G, Bliden K, Jindal M, Strickberger A. A randomized comparison of manual pressure versus figure-of-eight suture for hemostasis after cryoballoon ablation for atrial fibrillation. J Cardiovasc Electrophysiol. 2019;30(12):2806-10.

13. Calkins H, Kuck KH, Cappato R, Brugada J, Camm AJ, Chen SA, et al. 2012 HRS/EHRA/ECAS Expert Consensus Statement on Catheter and Surgical Ablation of Atrial Fibrillation: recommendations for patient selection, procedural techniques, patient management and follow-up, definitions, endpoints, and research trial design. Europace. 2012;14(4):528-606.

14. Barbetta I, van den Berg JC. Access and hemostasis: femoral and popliteal approaches and closure devices-why, what, when, and how? Semin Intervent Radiol. 2014;31(4):353-60.

15. Dangas G, Mehran R, Kokolis S, Feldman D, Satler LF, Pichard AD, et al. Vascular complications after percutaneous coronary interventions following hemostasis with manual compression versus arteriotomy closure devices. J Am Coll Cardiol. 2001;38(3):638-41.

16. Geis NA, Pleger ST, Chorianopoulos E, Muller OJ, Katus HA, Bekeredjian R. Feasibility and clinical benefit of a suture-mediated closure device for femoral vein access after percutaneous edge-to-edge mitral valve repair. EuroIntervention. 2015;10(11):1346-53.

17. Mahadevan VS, Jimeno S, Benson LN, McLaughlin PR, Horlick EM. Pre-closure of femoral venous access sites used for large-sized sheath insertion with the Perclose device in adults undergoing cardiac intervention. Heart. 2008;94(5):571-2.

18. Maraj I, Budzikowski AS, Ali W, Mitre CA, Kassotis J. Use of vascular closure device is safe and effective in electrophysiological procedures. J Interv Card Electrophysiol. 2015;43(2):193-5.

19. Shaw JA, Dewire E, Nugent A, Eisenhauer AC. Use of suture-mediated vascular closure devices for the management of femoral vein access after transcatheter procedures. Catheter Cardiovasc Interv. 2004;63(4):439-43.

20. Hamid T, Choudhury TR, Clarke B, Mahadevan VS. Pre-closure of Large-Sized Arterial Access Sites in Adults Undergoing Transcatheter Structural Interventions. Cardiol Ther. 2015;4(1):59-63.

21. Mylonas I, Sakata Y, Salinger M, Sanborn TA, Feldman T. The use of percutaneous suture-mediated closure for the management of 14 French femoral venous access. J Invasive Cardiol. 2006;18(7):299-302.

22. Hermiller JB, Leimbach W, Gammon R, Karas SP, Whitbourn RJ, Wong SC, et al. A prospective, randomized, pivotal trial of a novel extravascular collagen-based closure device compared to manual compression in diagnostic and interventional patients. J Invasive Cardiol. 2015;27(3):129-36.

23. Boer C, Meesters MI, Veerhoek D, Vonk ABA. Anticoagulant and side-effects of protamine in cardiac surgery: a narrative review. Br J Anaesth. 2018;120(5):914-27. 